\title{
Saline Water Intrusion Along the River Benthera and its Impact on Irrigation Water
}

\author{
Wijesundara K. and Piyadasa R.U.K.* \\ University of Colombo, Colombo 03, Sri Lanka \\ ranjana@geo.cmb.ac.lk
}

\begin{abstract}
Saline water intrusion is a major issue in the present era, and Benthara River has been affected with serious saline water intrusion along the river. The present study was conducted to identify sea water intrusion and its impact on irrigation system in the Benthera water scheme. In addition to that study objectives were to assess salinity levels in surface water with precipitation and tidal waves. The study area along the river is covered with mangroves and paddy. The research was conducted in the Ambalangoda irrigation area, Galle district in the southern province of Sri Lanka. Study area was located in the river Bentota and the left bank of the Benthara river basin irrigation scheme. Continuous monitoring was conducted over six months from January to June 2012. Five sampling points along the river from sea to ten kilometers $(10 \mathrm{~km})$ upstream were identified, based on two kilometers $(2 \mathrm{~km})$ interval inbetween sampling points. Further, three samples from three levels that is surface, mid stream and deeper level were taken from each collecting point. Laboratory analyses of chemical water quality parameters were observed.
\end{abstract}

The results revealed the $\mathrm{pH}$ and Electrical Conductivity (EC) of the river water are affected by sea water intrusion and other anthropogenic influences. Throughout the monitoring period EC values had not changed due to precipitation except with heavy rain. The study helped to prepare maps depicting salinity levels in the river using GIS software. It shows that most of the saline water goes through the river bed. Sea water intrusion occurs during afternoons of the time and EC values in February remained at the highest level of 32,900 micro Siemens per centimeter $(\mu \mathrm{s} / \mathrm{cm})$. The $\mathrm{pH}$ range varies from 6 to 7.5 in the morning and from 6 to 8 in the afternoon. Electrical Conductivity values of surface water in the study area were up to $32,900 \mu \mathrm{s} / \mathrm{cm}$ in the morning and $37,300 \mu \mathrm{s} / \mathrm{cm}$ in the afternoon. Chloride levels had significantly differed between the collecting point near the mouth of the river and the concluding point. Highest value of Chloride was 19,800 milligrams per liter $(\mathrm{mg} / \mathrm{l})$ in the morning and 20,692 $\mathrm{mg} / \mathrm{l}$ in the afternoon.

Keywords: Salinity, Tidal waves, $\mathrm{pH}$, Electrical conductivity, Irrigation 